\title{
The Challenges and Prospect of Qualitative Research in Accounting
}

\author{
Puji Handayati ${ }^{1, *}$ Shadi Emad A. Alhaleh ${ }^{2}$
}

${ }^{1}$ State University of Malang

${ }^{2}$ Zhongnan University of Economic and Law, China

*Corresponding email: puji226@yahoo.com,2Shadial2050@yahoo.com

\begin{abstract}
This study aims to comprehend the difficulties and the prospect of qualitative research in accounting, to investigate qualitative research capability in properly and effectively explaining accounting phenomena, and to investigate qualitative research impact on accounting. This study provides the rationale overview of qualitative research in accounting, discusses its theory development, provides a qualitative investigation principle guide, identifies qualitative common problems, gives a sufficient understanding of the challenges and how they affect the effectiveness, efficiency, and performance of the implemented accounting system. Accounting has confronted a ton of challenges pertaining to quickly evolving social, technological, economic, nature of policies, and global environment. This calls for accounting graduates' technical, non-technical, and generic accounting skills to get a meaningful job. Also, this study reviews the latest accounting literature and examines the major steps of its qualitative research. The research paper also provides potential future directions.
\end{abstract}

Keywords: qualitative research, the challenges and prospect of qualitative research, and accounting

\section{INTRODUCTION}

The application of qualitative methods in areas that should use traditionally quantitative methods must regard the challenges and the problems throughout the research, such as, different knowledge and skills. It demands the researcher's improved capabilities and knowledge about qualitative case study research to understand the details and have a clearer view of the research subject in the research setting [1]. A case study approach is suitable to describe, analyze, and understand both formal and informal processes existing in an organization. It offers an overwhelming advantage of a holistic view within a process, normally seen in details derived from both the observation and interviews. The observation allows to study distinctive features, observe the relation, and analyze the findings within the total environment.

According to Shank [2], qualitative research is a form of systematic empirical inquiry into meaning. Empirical means that it is planned, ordered, and approved by the qualitative research community. Empirically implies that this type of research is based on experience. Inquiry emphasizes that researchers try to understand how other people perceive their experiences.

Qualitative research involves a naturalistic and interpretive approach [3] as the researchers learn something in its natural settings, attempt to make sense of, or interpret phenomenon meanings to which people bring. It provides the researchers with the flexibility to follow unexpected ideas and explore processes efficaciously and contextual factor sensitivity. It also enables the researchers to study symbolic dimensions and social meaning as well as increase the opportunities to new theories and ideas empirically supported for longitudinal and in-depth phenomena explorations and for more relevance and interest $[4,5,6]$.

This research attempts to provide important ideas that will lead (1). To find out the main challenges of qualitative research in accounting, 
and to find out whether or not these challenges will be made if using qualitative methods to deal with them. (2). To find out how the qualitative method will provide satisfactory results in understanding accounting, and to find out whether it is possible to overcome the challenges by adopting the qualitative tools and techniques to deal with the research challenges. (3). To find out what the prospect for qualitative research in accounting looks like, and to find out how this prospect will play a role in analyzing and explaining the various phenomena of accounting aspect.

This study focuses on identifying the nature of qualitative research in order to observe the prospect and challenges in accounting, in addition to define the criteria of qualitative research through its definition, techniques, tools, data and information collection, and the main form of it. It also focuses on providing knowledge about how to use an effective qualitative method to interpret something such as understanding accounting regards to qualitative research, and obtain knowledge and document about its direct or indirect impact on accounting.

\section{LITERATURE REVIEW}

Talking about accounting and the different researches that have been made before in order to understand the principles, standards, assumptions, concepts, elements, terms, and procedures, rules, and policies of accounting. However, qualitative research is often used to predict, analyze and explain about the nature of accounting and the challenges faced by this kind of research in order to get a sufficient understanding about the different aspects of accounting. Moreover, qualitative research made a). To explore something about accounting that has not been discovered yet. b). To supply rich information, ideas, and documents existing knowledge about the challenges of the research area such as the field of accounting. (the challenges of qualitative research in accounting). c). To provide a better understanding about the topic by analyzing the basic definitions and give the right meanings which will lead to making a clear image about the concept, also will lead to reducing the limitations that could happen to understand that concept which regards the area of accounting. d). To provide a strong criterion including the basic elements of accounting. By using the qualitative method, it is going to be easy to explain these elements, because a qualitative method is useful and helpful to understand the different aspects of accounting, and it is not in doubt will lead to discovering the challenges that might face the qualitative research.

\section{RESEARCH METHOD}

Qualitative research is completely related to social science, so it will not be difficult to find out what challenges which still to be explained by the scope of qualitative research. Regarding qualitative research in accounting, qualitative research investigates social phenomena from the accountant's perspective and any party involved in order to reach the main reasons, results, and causes that lead to creating challenges and obstacles in understanding what this research for.

These paragraphs that have been written in this study are to understand the things that cover accounting. From the authors' perspective, qualitative is more important than quantitative, it because qualitative research has direct contact with others in order to get the right information and ideas that will explain and analyze the problems and the questions of the research. Analyzing and understanding policies in order to find out the strengths and weaknesses of these policies, then criticizing them. This will lead to acquiring sufficient knowledge of accounting and consequently to aware of the challenges of qualitative research and find out how to implement the qualitative practice correctly in order to identify the various threats to the practice of accounting, to identify the various challenges faced in practicing accounting, and to examine the relationship between these challenges and the development of accounting by depending on the qualitative method.

\subsection{The qualitative Research Challenges in Accounting}

The challenges deal with the accessibility to the organization's lingual, cultural, and social issues. Researchers often have difficulty in entering and being accepted into organizations in which being their object of the study. This is especially valid if the research design of a case study is used as the organization is under close supervision aperiodically. Today's researchers meet the challenges to gain organizational access in line with Baird's finding [7].

Most companies do not let researchers attend, observe their formal meetings, and access the documents. For example, the researchers have to 
wait for more than one month for the meeting observation. Nonetheless, after pertinacious negotiations with gatekeepers, the researchers were allowed to attend one or two meetings during the visits. In addition to the observation issue, document access highly vital for triangulation and validity arose difficulties to review company documents such as meeting reports, company magazines, and annual reports, which finally could be accessed after tediously protracted negotiations, social and cultural norm observance.

\subsection{Cultural and Language Challenges in the Local Context}

The disappearance of meaning from the interview will affect the study validity. However, facing this difficulty ensures that the actual meaning does not disappear from the original interview text. This is something that researchers are very afraid of. The use of respondents' language ensures that they are culturally relaxed and more readily identifiable to interviewers. This is also an important point in getting approval for doing an interview because people cannot conduct an interview without the consent of the source [1].

\section{RESULTS AND DISCUSSION}

\subsection{Interviews in Qualitative Research}

The interview is an effective data collection method since it provides an opportunity to call for clarification of questionnaire answer vagueness. It is the researcher's main tool of data collection from employees. With a tape recorder, the researcher could fully concentrate on the interviewees' answers as well as observe their non-verbal behaviors thoroughly. However, the researcher encountered is the refusal of all participants, except one, to use the tape recorder for the interviews [8]. The researchers have no specified or clear background on qualitative research, and this is considered as one of the basic challenges to conduct a research in accounting, so the accountants have no idea about creating a strong qualitative research in order to understand important aspects of accounting. The challenges of qualitative research, it could be ethical challenges and it is really sensitive to understand different aspects of accounting, when the accountants or participants give unclear information or misleading ideas about the topic area, with no doubt this is going to be the biggest challenge to conduct a qualitative research in accounting. Other challenges are defending qualitative method ethical principles and reassuring the participant's exclusive theoretical and academic interests [9, 10]

In addition, a lack of experience, skills, and knowledge of qualitative research methodology could block the original knowledge formation and understanding improvement of accounting phenomenon. This might avoid the research result's novelty and interestingness. Even, the research process will be highly unmanageable in the absence of proper interpretation or adequate exploration about accounting aspects, and this challenge should be taken into consideration while making or conducting qualitative research in accounting, in addition to knowing how to adopt a strong experience to overcome this challenge of doing qualitative research $[9,10]$.

Besides, the decision on proper research methodology should be made. It is novice researchers' main concern to select the appropriate design, as well as the reasons, and the proper methodology for their research questions. They need to figure out their qualitative research planning and how to select the methodology that suits the purpose of the topic area (accounting), and suits how to conduct the research correctly and effectively to obtain satisfying results about interpreting accounting aspects.

Qualitative research also bears the accusation challenge of being a manipulative approach enabling researchers to speculate the data meaning in the favor of personal agenda. This will lead to creating too many obstacles and challenges about analyzing the study aspects of accounting. The challenge of Incorporating online technologies. While making e-mail interviews beneficial for the case study completion and the qualitative open-ended online questionnaire implementation, addressing the participants' feelings and attitudes towards the practices to obtain original and direct participants' reasoning on their study are proved to be more practically challenging. Questioning the method's validity and reliability emerged, especially considering the lack of support from similar research in the academic literature.

Therefore, the practical challenges in the field of accounting and of performing interpretive research are based on professional experience and available literature. However, the problems of qualitative research lead to creating unpredictable challenges such as a problem that may connect with factors such as generally qualitative research is simply a case study with limited applicability to other situations. It also gives nominal level data 
which is difficult to quantify, and it is hard to control the researcher's bias. Also, the weaknesses of qualitative research lead to creating challenges such as the consequences of reliability which has difficulty in replicating findings, the risk of collecting meaningless and useless information. Addedly, since the observations might be reported selectively, it is impossible to gauge the extent to which their typical character, the subjectivity of nature of data collection and analysis, and highly timeconsuming, and other issues that explain the basic challenges to conducting qualitative research in interpreting accounting studies $[11,12]$.

Explanation about the basic definitions of this paper:

1. Shank [2] selectively described qualitative research as a form of systematic empirical inquiry into meaning. As stated by Denzin and Lincoln [3], qualitative research involves an interpretive and naturalistic approach. It learns in its natural settings and interprets the meaning of the phenomena. So, to conduct a qualitative research in accounting, what the researchers aim to do?

Qualitative researchers aim to gain an in-depth understanding of accountants' acts and behaviors, and the reasons behind the behaviors. In addition, the qualitative method looks into why and how, we should create decisions making instead of asking or not just what, where, and when, and that is in order to get clear information and ideas about the accounting studies.

2. Qualitative challenges and prospects: These challenges prevent research from achieving its main objectives and creating many weak points in the main body of research such as ethical issues, reliability issues, and the subjectivity of nature data collection and analysis, in addition to other challenges that do not qualify qualitative research becomes one of the scientific researches in order to deal with different difficulties, and then to find suitable solutions for it. Meanwhile, a qualitative prospect is used to fulfill the purpose of social responsibility to develop a science reflexive and critical understanding, to promote sex equality in any scientific activities, and to promote research suitable to the subject taking account to historical and social (cultural) conditions of accounting studies and oriented towards every day's practices and lives, to provide scientific support, reflect accounting practices as well as take up and renew the social, cultural and intellectual science traditions to act on interdisciplinary cooperation to develop the professional identity despite the huge variety of discourses for which should be striven.

3. Accounting is about a comprehensive and systematic financial report of a business. It also covers summarizing, analyzing, and reporting the transactions oversight tax collection entities and agencies.

\subsection{Qualitative Prospects Inside the Accounting Field}

The main expectations of qualitative research in accounting lead are to find out how to overcome the challenges, in order to predict good expectations about improving and developing the different aspects of accounting, meanwhile, qualitative research still attempts to understand the accounting nature in-depth, in order to diagnose the main problems and in order to design the right methodology to deal with these problems as well.

Regarding the prospect of qualitative research, that prospect will lead to expect the basic principles and procedures that should be taken into consideration in order to discover the obstacles of accounting as quick as possible and then trying hard to eliminate them by adopting effective strategies that will be used to overcome these obstacles. Also, the prospect's purpose is to give important explanations about something that has been explored before, and the qualitative research prospects in accounting will estimate the positive aspects in order to achieve something, and that is after recognizing or identifying and analyzing the main challenges that have been faced. However, the development in the prospect of qualitative research needs more documents and conclusions that will provide sufficient knowledge about how to estimate the positive side of the accounting studies, and it is necessary to focus on the challenges of the research in order to know how to establish a strong structure for creating suitable qualitative research with suitable design to clarify the future prospect in accounting.

Thus, qualitative research calls attention to the social world and provides the instruments to investigate accounting phenomena from the perspective of those who experienced them, and to obtain information from them, and this information will be used to evaluate or to support the prospect of qualitative research. Analyzing and explaining the qualitative research prospect in accounting leads to the question of why it is chosen in the accounting professions and to 
answer the question, we should know the main expectations of the researchers, which might be helpful to minimize the problems and difficulties in understanding accounting aspects.

According to the prospect of qualitative research, should researchers justify the reason for which they choose qualitative research? Qualitative researchers act on exclusive perspectives. The approach is highly essential to comprehend human experiences in relation to accounting. This is beneficial for accounting professionals as they act on communication, caring, and interaction. In fact, according to Kapoulas [11], the reasons for adoption qualitative prospect in accounting return to:

- People perceptions, emotions, and actions who get sufficient knowledge about accounting issues comprehendible by qualitative research.

- The accounting profession's meanings will merely be unrevealed by observing the professionals' interactions with clients and conducting interviews about their experiences.

- As qualitative research is individualized, meanwhile, the participants are considered as whole human beings, rather than physical living organisms. The observation and interviews are the only ways to translate the particular behavior causes.

The prospect of qualitative research in accounting leads to justify important points such as increasing social importance of accounting services, qualitative research is strongly connected with the society in order to explore or to predict human act and behavior, meanwhile, the social importance of accounting services in many fields of practice is enormously growing recently and sets to more radically expand in future. However, the extent to which the increased importance is also directly accompanied by accounting service demands, and whether the demands are aimed at qualified and trained accountants, is another question.

The future prospects for accounting related to qualitative research. This study predicts how to improve different aspects in accounting in order to meet the requirements, and in order to create a rational basis of usable training syllabuses with critical debate in social responsibility. Thus, through the analysis of human's ethical and behavioral acts in society, this will be easy to estimate the future prospect in accounting, and it will meet the required changes that should be adopted during the estimations of these prospects in the field of accounting.

The current contact practice among other methodological positions within scientific research in accounting is really necessary to predict the future and current practice of accounting through adopting different qualitative researches and through focusing on how the prospect of this research will affect the expectations of this practice. Therefore, a different culture of discourse is necessary to establish scientific research in accounting as a key precondition for a strong position of accounting in the canon of subjects. Meanwhile, the other social sciences, retrospectively, can already claim in creating different theories that will be held on explaining the different perspective of sociology studies rather than other studies.

The prospect of qualitative research will provide strong criteria by which to analyze accounting policies and procedures and understand the key context for accounting disclosure. This is conducted in order to design a robust methodology from qualitative research available. Meanwhile, accounting services and the disclosure policy research can rely on qualitative research methods, particularly when coping with a rapid change and the development of integrated theoretical base and research agenda. The accounting field, nevertheless, must have a good tradition and technique of qualitative methods and distinguish the special training and experience essences while applying these specific methods $[13,14]$.

\section{CONCLUSIONS}

Based on the result of the study, it can be concluded as 1). The challenges of qualitative research in accounting cannot be avoided if we more focus on the methodology of the research rather than the design, because adopting a strong qualitative research requires a good design that suits the research criteria in order to deal with the research problems and questions and to achieve the purpose of the research which will lead to reducing the challenges of conducting qualitative research in accounting. 2). Getting access to know how or what the challenges are and what the prospect of qualitative research in accounting. The researcher should make a certain consideration to the selected area as the basis of the research and that a qualitative project is possible and relevant. Properly forming the research question and selecting the proper 
methodology guarantees the knowledge originality, interestingness, and applicability. This at least highly will increase the understanding of the meaning of certain accounting conditions and how, in a particular social context, their relationships are built. 3). An accounting comprehension related to the qualitative research, usually based on the type and essence of the research questions, the researcher's epistemological knowledge, capabilities, training, skills, and stances, as well as the available resources, which are the criteria upon which the adopted methodology and procedures depend on that research. 4). To gain a positive qualitative research prospect, it is vital to consider thorough planning within all research process stages, starting from question development to finding the final write-up. It is worth knowing that some of the qualitative research project details cannot be ascertained in advance and could be specified during the research process. 5). The logical challenge of being clear about conducting qualitative research in accounting is to know how to obtain knowledge that will meet a rapid change that might happen in the different accounting aspects. 6). Inconsistency between qualitative research questions and its methodology, insufficient knowledge about accounting information and its procedures, and the lack of attention to the philosophical underpinnings of qualitative research methodology are some significant challenges.

\section{REFERENCES}

[1]. F. Breuer, K. Mruck, W. M. Roth, Subjectivity and reflexivity: An introduction, Forum Qualitative Sozialforschung 3(3), 2002.

[2]. G. Shank, Qualitative research: A personal skills approach, Merrill Prentice Hall, New Jersey, 2002.

[3]. N. K. Denzin, L. S. Lincoln, Handbook of qualitative research. Sage Publisher, London, 2000 .

[4]. M. Alvesson, Leadership studies: From procedure and abstraction to reflexivity and situation. Leadership Quarterly 7(4), 1996, pp. 455-485.

[5]. A. Bryman, M. Bresnen, A. Beardsworth, T. Keil, Qualitative research and the study of leadership, Human Relations 41(1), 1988, pp. 13-30.

[6]. J. A. Conger, Qualitative research as a cornerstone methodology for understanding leadership, The Leadership Quarterly 9(1), 1998, pp. 107-121. DOI:10.1016/S10489843(98)90044-3.

[7]. M. Baird, Comparing cases: Studies of commitment system in Australia and the United States, International of Human Resource Management 5(3), 2004, pp. 433440.

[8]. A. Tashakkori, C. Teddlie, Mixed methodology: Combining qualitative and quantitative approaches. Sage Publisher, California, 1998.

[9]. K. D. Ruyter, N. Scholl, Positioning qualitative market research: Reflection from theory and practice, Qualitative Market Research: An International Journal 1(1), 1998, pp. 7-14.

[10]. S. D. Hunt, On rethinking marketing: Our discipline, our practice, our methods, European Journal of Marketing 28(3), 1994, pp. 13-25.

[11]. A. Kapoulas, W. Murphy, N. Ellis, Say hello, wave goodbye: Missed opportunities for electronic relationship marketing with the financial services sector, International Journal of Bank Marketing 20(7), 2002, pp. 302-313.

[11]. K. M. Eisenhardt, Building theories from case study research, Academy of Management Review 14(4), 1989, pp. 532550.

[12]. G. Morgan, L. Smircich, The case for qualitative research, The Academy of Management Review 5(4), 1980, pp. 491-500. DOI:10.2307/257453.

[13]. Y. G. Lincoln, E. G. Guba, Naturalistic inquiry. Sage Publisher, Newbury Park, CA, 1985. 